\title{
EN LA BIBLIA HEBREA: IMPLICACIONES CRISTOLÓGICAS
}

\author{
Evandro Luiz da Cunha
}

\section{Introducción}

En el presente artículo nos proponemos exponer la pragmática y la semántica de יִ en el Tanaj. No es tarea sencilla establecer bases semánticas seguras sobre una voz como esta de la que tenemos un corpus tan restringido de textos en los que ocurre. Para intentar iluminar algunos aspectos un tanto oscuros, se compara el texto griego de la Biblia Hebrea (BH), la LXX, con el Texto Masorético (TM). ${ }^{1}$ Además de arrojar luz sobre el TM, la LXX fue el texto usado por los primeros cristianos para elaborar su cristología y su concepción de la Divinidad, tal como la encontramos en el

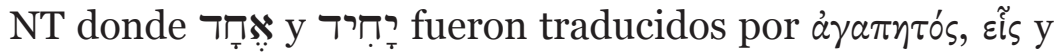
róvos. Por esta razón hemos decidido tener en cuenta en la discusión el texto en griego de la LXX, como forma de ofrecer más elementos de ayuda para aquellos que desean reconstruir el recorrido semántico-teológico de יָדידיד.

Los comentarios que presentamos a continuación no abarcan una exposición del texto en su totalidad sino tan solo de los aspectos lingüístico-literarios e históricos que puedan dilucidar la semántica de יָדיד. Las cuestiones de crítica textual solo serán incluidas cuando resulten relevantes para una mejor comprensión de la perícopa.

${ }^{1}$ Hay una diferencia en la numeración entre el TM, la LXX y la RV60 en algunos textos. 


\section{en la Torá}

En la Torá, ידידיד es usado solamente en Génesis. No obstante, el uso en este libro influye en todo el imaginario colectivo hebreo desde la época de Abraham hasta nuestros días. ${ }^{2}$

\section{ירָיחיד en Génesis}

\section{Propedéutica}

Al considerar el Génesis como una unidad literaria, ${ }^{3}$ el contexto temático inmediato de la perícopa son los capítulos 20 y 21. ${ }^{4}$ En el capítulo 20 encontramos a Abraham y Abimelec, rey filisteo. La estructura desde el punto de vista semiótico es muy interesante por el juego de palabras existente pues los dos personajes tienen nombres compuestos usando el mismo sustantivo, אָָ, "padre". Abraham (padre

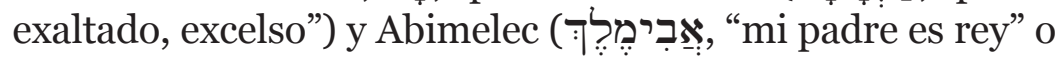

${ }^{2}$ La ideología de la sustitución derivada de este suceso ha influido el monoteísmo en sus distintas manifestaciones. En el judaísmo, p. ej., la experiencia de Abraham-Isaac es invocada como ideología religioso-revolucionaria en 4 Macabeos 13:9-12; 1:18-20; El poema de las cuatro noches del Targum Neofiti hace mención de la 'áqedâh (el sacrificio) de Isaac en Éx 12:42 donde se sugiere que Isaac tendría 37 años en aquella ocasión. Stephen A. Kaufman, ed., Targum Neofiti to the Pentateuch (Cincinnati: Hebrew Union College, 2005). En el Targum Pseudo Jonatán se dice que Isaac era de 36 años ( $\mathrm{Gn}$ 22:1). Stephen A. Kaufman, ed., Targum Pseudo-Jonathan to the Pentateuch (Cincinnati: Hebrew Union College, 2005). En cambio, Flavio Josefo dice que la edad de Isaac era de 25 años. Flavius Josephus, Antiquities of the Jews, 1.227. Para una visión de la influencia actual de la 'áqedah (sacrificio) de Isaac, véase Louis Jacobs y Avi Sagi, “Akedah”, Encyclopaedia Judaica, ed. Fred Skolnik, 2da. ed. (Jerusalem: Keter Publishing House, 2007), 1:555-9.

${ }^{3}$ Para el análisis de los diferentes pasajes bíblicos en este artículo, cada libro analizado es considerado una unidad literaria.

${ }^{4}$ Para tener una visión general de la estructura de la perícopa, véase Gordon J. Wenham, Genesis 16-50, Word Biblical Commentary (WBC) 2 (Dallas, TX: Word, 2002), 99-103. 
"Moloc es rey"). ${ }^{5} \mathrm{El}$ relato narra que Abraham le dice una media verdad a Abimelec al decirle "Sara es mi hermana". Por tal motivo, Abimelec toma a Sara como mujer. Sin embargo, antes de consumar el matrimonio, YHWH se le aparece en sueños advirtiéndole del asunto. Abimelec confiesa su inocencia y Dios dice haber encontrado en él integridad de

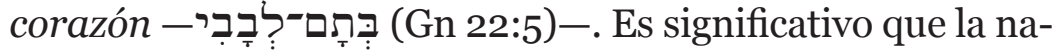
rrativa usa este mismo vocablo en el contexto del llamado de Abraham, quien debía caminar en presencia de YHWH buscando integridad, perfección y madurez) - - רָדִ - es decir, fidelidad a la alianza (Gn 17:1). La semántica estructural del texto revela que Abimelec había alcanzado un alto grado de fidelidad a YHWH, mientras que Abraham caminaba en la dirección ética opuesta. Este dato es esencial para comprender el capítulo 22 de Génesis. La infidelidad de Abraham en el capítulo 21 es revertida en el capítulo 22.

En el capítulo 21 encontramos el nacimiento de Isaac (vv. 1-6), Agar e Ismael son expulsados de la casa de Abraham (vv. 8-21) y finalmente se da el pacto entre Abraham y Abimelec (vv. 22-33). En este capítulo la prueba de Abraham es el trato que da a su hijo mayor y a su concubina. En la estructura sintagmática del v. 14, Abraham se levanta temprano para despedirse de Ismael y Agar. Si comparamos con 22:3, deducimos que el narrador sugiere que para Abraham esta separación fue un tipo de sacrificio, una renuncia que solo fue llevada a cabo después de su reacción indignada

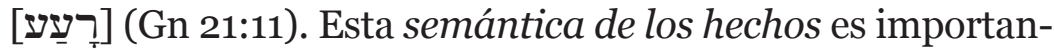
te para comprender el significado de יִחיד.

En el capítulo 22 Abraham es desafiado con una prueba mayor que la anterior. Aquí asume un papel totalmente inverso a los anteriores aceptando el nuevo desafío. Los sa-

${ }^{5} \mathrm{Si}$ se considera la yod de ción sería "padre de rey". 
crificios humanos (incluyendo los de niños) eran comunes en la época. ${ }^{6}$ Ofrecer el hijo en holocausto no era algo extraordinario sino común. Entonces, ¿̇por qué YHWH se deleita con la actitud de Abraham?7 Porque Abraham iba a ofrecer su יָחיָיד.

Textos y contextos

Vamos a repasar esos tres textos en general y a continuación haremos un análisis inclusivo sobre el significado de en en Génesis.

Los tres versículos empiezan con la misma cláusula verbal: "y dijo" (רַיאמֶמר). YHWH es el sujeto en los vv. 2 y 12. En el v. 16, el sujeto es el mensajero de YHWH.

Génesis 22:2: Y dijo: Toma ahora tu hijo, tu único, Isaac, a quien amas, y vete a tierra de Moriah, y ofrécelo allí en holocausto sobre uno de los montes que yo te diré.

La cláusula wayyiqtol "aconteció después de estas co-

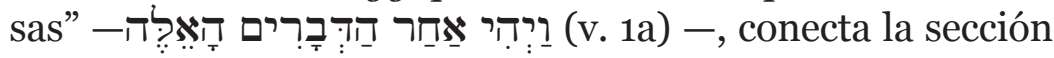

${ }^{6}$ Alberto Ravinell Whitney Green, The Role of Human Sacrifice in the Ancient Near East, American Schools of Research Dissertation Series 1 (Missoula, MT: Scholars Press, 1975); John H. Walton, Victor H. Matthews y Mark W. Chavalas, eds., Genesis, IVP Bible Background Commentary: Old Testament (Downers Grove, IL: InterVarsity, 2000), 53.

${ }^{7} \mathrm{El}$ autor del libro de Jueces no enaltece la actitud de Jefté al sacrificar a su única hija después de hacer un voto precipitado (Jue 11).

${ }^{8}$ Para más información sobre la estructura narrativa del TM, véanse Joel S. Baden "The Wayiqtol and the Volitive Sequence", Vetus Testamentum 58 (2008): 147-158; Tania Notarius, "Prospective Weqatal in Biblical Hebrew: Dubious Cases or Unidentified Category?”, Journal of Northwest Semitic Languages 34, no. 1 (2008): 39-55; Robert C. Culley, ed., Perspective on Old Testament Narrative, Semeia 15 (Missoula, MT: SBL, 1979). 
anterior con la narrativa que empieza de forma enfática:9 "y

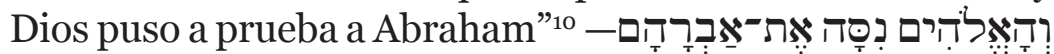
(v. 1b)-. ${ }^{11}$ En la estructura discursiva, siguiendo a Greimas, ${ }^{12}$ la temporalización de la escena que se va a desarrollar no pretende presentar una cronología exacta de los sucesos, sino tan solo especificar que estos hechos ocurrieron después de "muchos días" (יָמִים רַברבים) de que Abraham viviera en tierra de los filisteos (Gn 21:34) - espacialización-. En la actorialización tenemos a Dios, a Abraham, a Isaac, a dos siervos y al ángel de YHWH.

Estructura del texto:

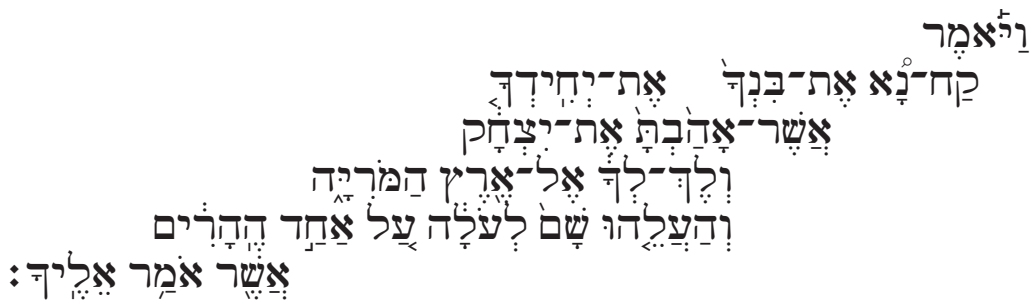

${ }^{9}$ Barry, Bandstra, "Word Order and Emphasis in Biblical Hebrew Narrative: Syntactic Observations on Genesis 22 From a Discourse Perspective", en Linguistics and Biblical Hebrew, ed. Walter R. Bodine et al. (Winona Lake, IN: Eisenbrauns, 1998), 108-23.

${ }^{10}$ Traducción propia.

${ }^{11}$ Frederic Clarke Putnam, Hebrew Bible Insert: A Student's Guide to the Syntax of Biblical Hebrew (Quakertown, PA: Stylus, 2002), 42.

${ }^{12}$ Véase Joseph Courtés, Introducción a la semiótica narrativa y discursiva: Metodología y aplicación (Buenos Aires: Hachete, 1980); Algirdas Julien Greimas, Semántica Estructural: Investigación Metodológica. (Madrid: Editorial Gredos, 1987); Algirdas Julien Greimas y Joseph Courtés, Dicionário de Semiótica (São Paulo: Editora Cultrix, 1979). 
Siguiendo las directrices de la teoría tagmémica,13 se encuentra insertado en un estado constructo encadenado y su función es la de adjetivo, es decir, que tiene la función de especificar, cualificar el referente -el sustantivo ’ ("hijo")-. Esta es la primera vez que este vocablo es registrado en el texto bíblico. ¿̇Por qué se hace uso de יִדיד aquí y no se optó por otros términos? En Génesis encontramos vocablos con ideas similares a יִיָדיד. Por ejemplo, ("solo, únicamente; débil, ciertamente") que es usado en 13 ocasiones. ${ }^{14}$ Encontramos también ("solo, únicamente, aislamiento, separado, puesto aparte") que se encuentra registrado 14 veces en este libro. ${ }^{15}$ Gadamer decía que el uso de un término en lugar de otro que es más común, puede denotar simplemente una cuestión estético-literaria o una intencionalidad semántica. ${ }^{16}$

Las versiones clásicas y modernas traducen ירָידיד por "único". La LXX hizo una traducción interpretativa usando

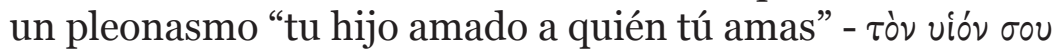

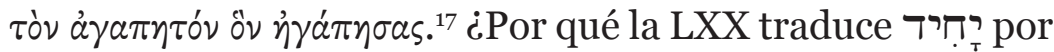
àramitós? Más aún cuando la voz hóvos ("único”, "solo",

${ }^{13}$ Véanse A. L. Becker, “A Tagmenic Approach to Paragraph Analysis”, College Composition and Communication 16, no. 5 (1965): 237; Evelyn G. Pike, "How I Understand a Text - Via the Structure of the Happenings and Telling of Them", en Discourse Description: Diverse Linguistic Analyses of a Fund-raising Text, ed. William Mann y Sandra A. Thompson (Amsterdam: John Benjamins, 1992), 228-9. $50: 8$

${ }^{14} \mathrm{Gn} 6: 5 ; 14: 24 ; 19: 8 ; 20: 11 ; 24: 8 ; 26: 29 ; 41: 19-20,27,40 ; 47: 22,26$;

${ }^{15} \mathrm{Gn} 2: 18 ; 21: 28-29 ; 26: 1 ; 30: 40 ; 32: 17,25 ; 42: 38 ; 43: 32 ; 44: 20 ;$ $46: 26 ; 47: 26$.

${ }^{16}$ Hans-Georg Gadamer, "Semántica y hermenéutica (1968)", en Verdad y Método II, trad. Manuel Olasagasti, 7ma ed. (Salamanca: Sígueme, 1992), 178.

${ }^{17}$ Traducción propia. 
“solamente") $)^{18}$ usada frecuentemente para traducir ("solo, separado, aislado", etc.) ${ }^{19}$ estaba disponible en la lexicografía griega. Filón acuñó la cláusula "el amado y único"

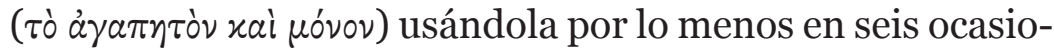
nes y la mitad de las veces en relación con la experiencia de Abraham-Isaac. ${ }^{20}$ Nos encontramos también con que Flavio

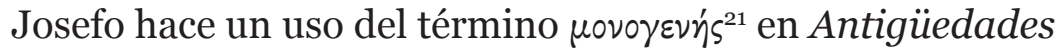
Judías para describir al unigénito. En esa fuente, en 1.222, Josefo hace mención de Gn 22; en 2.181 alude a Dan que tenía un único hijo (Hushim); en 5.264 lo relaciona con Jue 11:34; finalmente, en 20.20 lo vincula a un incidente secular (alguien que tenía muchos hijos, pero que sentía predilec-

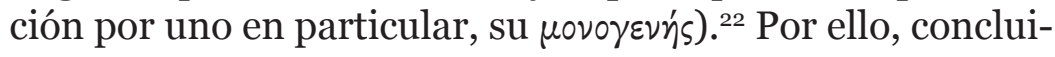
mos que en la LXX se quiso agregar un nuevo sentido a ירחיד. En cambio, no es posible deducir a partir del TM del Génesis que ירזיחיד tuviera la connotación de "único" (teniendo en cuenta que Abraham tenía otro hijo), y aunque la noción de "amado" sería un pleonasmo (común en el hebreo

${ }^{18}$ H. G. Liddell, A Lexicon: Abridged from Liddell and Scott's Greek-

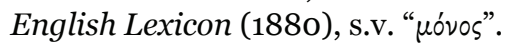

${ }^{19}$ Francis Brown, con S. R. Driver y Charles A. Briggs, A Hebrew and English Lexicon of the Old Testament With an Appendix Containing the Biblical Aramaic, based on the lexicon of William Gesenius (1952), s.v. “ד”. Cf. Gn 2:18; Éx 12:16, 37; Dt 1:9, 12; 14:16, 18; Dn 10:7; 11:4; Zac 12:12.

${ }^{20}$ Philo, De Abrahamo, 1.168; Philo, Legum allegoriarum, 3.203; Philo, Quod Deus sit immutabilis, 1.4; Philo, De ebrietate, 1.30; Philo, De sommiis, 1.194; Philo, De vita moris, 1.13 Tenemos también una referencia a Gn 22 en Philo, De somniis, 1.195 .

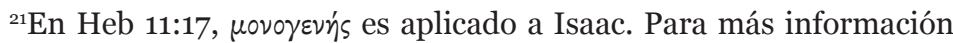
sobre la pragmática cristiana de este término, véase Lc 7:12; 8:42; 9:38; Jn 1:14, 18; 3:16, 18; Heb 11:17; 1 Jn 4:9.

${ }^{22}$ Véase también Josephus, The Works of Josephus: Complete and Unabridged, New Updated Edition, trad. William Whiston (Peabody, MA: Hendrickson, 1987). 
bíblico), ${ }^{23}$ de cualquier modo esto sería admisible.

En el v. 12, Abraham había llegado a su destino y enseguida estuvo listo para ejecutar el mandato divino, cuando un ángel intervino.

Génesis 22:12: $Y$ dijo: No extiendas tu mano sobre el muchacho, ni le hagas nada; porque ya conozco que temes a Dios, por cuanto no me rehusaste tu hijo, tu único.

Estructura del texto:

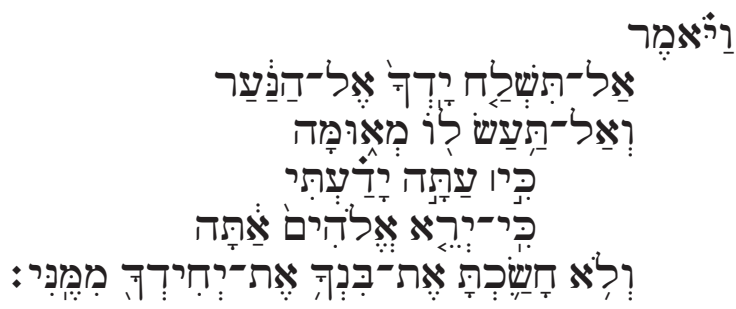

Como en el verso anterior, יִדיד forma parte de un estado constructo aquí también con función adjetival. Por otro

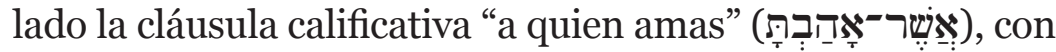
la función de adjetivo ("el amado") usado en el v. 2, está ausente aquí. Sin embargo, los comentarios del v. 2 sirven también para los vv. 12 y 16 puesto que la semántica de יָדיד no difiere de la de los otros versos.

Finalmente, el v. 16 cierra el ciclo de tres veces que la

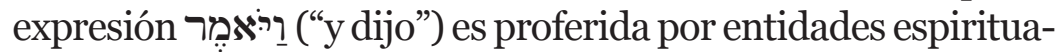
les en este capítulo y estructura, en cierto modo, la narrativa.

${ }_{23}$ "Mas Sara era estéril, y no tenía hijo" (Gn 11:30). Véase Moses Stuart, A Hebrew Grammar With a Praxis on Select Portions of Genesis and the Psalms (Andover: Codman Press, 1823), 373-4. 
Génesis 22:16: y dijo: Por mí mismo he jurado, dice Jehová, que por cuanto has hecho esto, y no me has rehusado tu hijo, tu único hijo;

Estructura del texto:

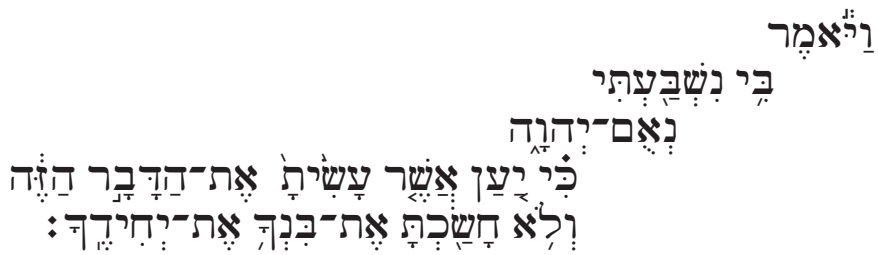

El verso presenta una variante, ${ }^{24}$ aunque no cambie en nada la semántica del texto. Contiene un cierto tono judicial

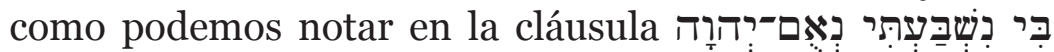
("por mí mismo he jurado, dice Jehová”, o más literalmente “declaración o sentencia de YHWH”). El término נִִ̣ está íntimamente relacionado con los oráculos proféticos y jurídicos. ${ }^{25}$ En el libro de Génesis es un hapax legomenon. El término ריחיד concluye el verso como parte de un estado constructo lo mismo que en los versos anteriores ( 2 y 12) y su sentido permanece inalterable.

Síntesis de רִידִ en en Génesis

es usado en el capítulo 22 en tres ocasiones (vv. 2,

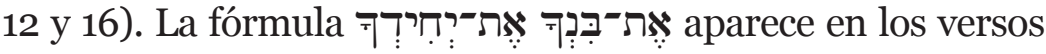

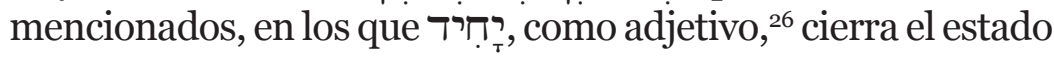
tensia (BHS).

${ }^{24}$ Véase la nota crítica sobre Gn 22:16 en la Biblia Hebraica Stuttgar-

${ }^{25} \mathrm{Gn}$ 22:16-18; Nm 14:28; Is 14:22; 30:1; 59:20; Jer 15:15; 19:6; Ez 18:3, 9; et al.

26“"Todo adjetivo que modifica cualquier sustantivo debe ser puesto al 
constructo modificando el sustantivo referente.

En el libro de Génesis encontramos la partícula adver-

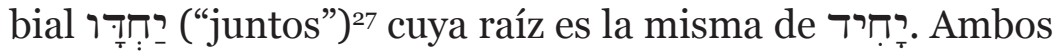
términos pertenecen, pues, al mismo campo semántico, lo cual "implica una comunión de propósito" ${ }^{28}$ En este capítulo, ביחדָדָ es usado en los vv. 6, 8 y 19. En los vv. 6 y 8 la idea se ve reforzada con el numeral dual constructo usado como

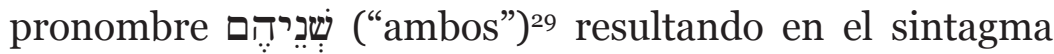
“ambos juntos”. Para Rashí, esta expresión “implica que lo hicieron con corazón unánime”. ${ }^{30}$ En Génesis, es usado solo para la relación interpersonal. ${ }^{31}$ En el v.

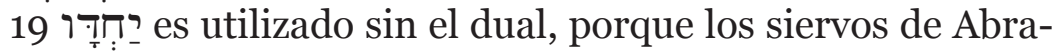
ham también estaban involucrados. El Tárgum de Onkelos de Gn 22:6 dice, literalmente, que los dos (Abraham e Isaac)

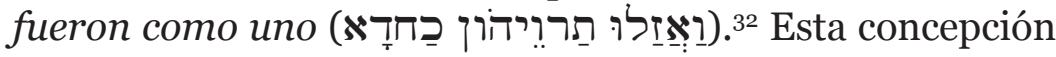
encuentra su paralelo en Gn 2:24. ${ }^{33}$

Podemos deducir, a partir de un análisis comparati-

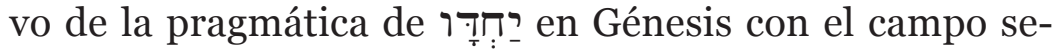

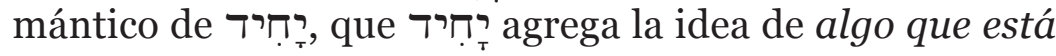

final de la cadena [constructa]". Thomas O. Lambdin, Gramática do Hebraico Bíblico (São Paulo: Editora Paulus, 2003), 100.

${ }^{27} \mathrm{Gn}$ 13:6; 22:6, 8, 19; 36:7.

${ }^{28}$ Aryeh Coffman, La Torá con Rashí: El Pentateuco con el comentario de rabí Shelomó Itzjakí (Rashí) (México: Editorial Jerusalén de México, 2001), 280.

${ }^{29}$ Lit. "dos de ellos".

${ }^{30}$ Coffman, La Torá con Rashí, 281.

${ }^{31} \mathrm{Gn} 2: 25 ; 3: 7 ; 9: 23 ; 21: 27,31 ; 22: 6,8 ; 40: 5 ; 48: 13$.

${ }^{32}$ Stephen A. Kaufman, ed., Targum Onkelos to the Pentateuch (Cincinnati: Hebrew Union College, 2005).

33"Por tanto, dejará el hombre a su padre y a su madre, y se unirá a su mujer, y serán una sola carne”. 
muy cercano, junto. Este concepto estructura todo el relato. Isaac es el hijo que está junto al padre. Ismael y los otros hijos de Abraham son descritos como estando en una tierra lejana (21:8-21 y 25:6). Isaac es el "único", porque está sólo. Además, recibe toda la herencia de Abraham (25:5). Isaac es el hijo prometido (cf. Gn 12, 15, 18 y 21). Esto implica profecías mesiánicas (Gn 3:15) y tal vez justifique la admiración de YHWH ante la actitud de Abraham quien no solo estaba dispuesto a sacrificar a su hijo amado, sino a un hijo que además incorporaba más que sentimientos paternales; incorporaba, la esperanza de un pueblo: "Y haré de ti una nación grande, y te bendeciré, y engrandeceré tu nombre, y serás bendición. Bendeciré a los que te bendijeren, y a los que te maldijeren maldeciré; y serán benditas en ti todas las familias de la tierra" (12:2-3).

Isaac es el hijo que permanece en casa. Él es el de de Abraham: El único heredero prometido. ${ }^{34}$ Este es el concepto esencial de en en el libro de Génesis.

\section{רִיחִיד en los Nevi’im (Profetas)}

En la sección de los Neviðim, ירחיחיד aparece en los Profetas anteriores (Jueces) y posteriores (Jeremías, Amós y Zacarías).

רידר? en Jueces

Propedéutica

La temporalización del libro de Jueces cubre el período entre la teocracia inaugurada por Moisés y la instauración de la monarquía. Después de la muerte de Josué, Israel entró en declive espiritual y político (Jue 2:6-10 y 11-23). Una su-

${ }^{34} \mathrm{El}$ Tárgum de Pseudo Jonatán recrea un diálogo hipotético entre Ismael e Isaac sobre la legitimidad del heredero en Gn 22:1. 


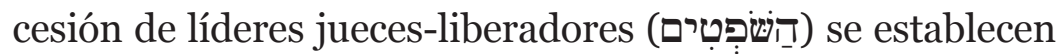
como gobernantes para ejercer una doble función militar y

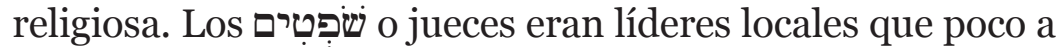
poco asumieron un liderazgo regional y, en alguna ocasión, hasta nacional. La narrativa gira en torno a las vicisitudes de las tribus que componen la etnia de Israel. Se trata de una época marcada por la ausencia de un poder central donde "cada uno hacía lo que bien le parecía" (Jue 17:6; 21:25).

Tras la muerte de Jair, "los hijos de Israel volvieron a hacer lo malo ante los ojos de Jehová" (Jue 10:6). La cláusula

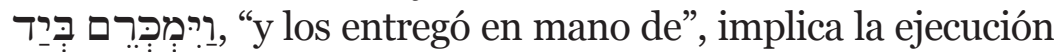
de una sentencia (Jue 10:7). Bajo la opresión extranjera Israel clama por la liberación. Es en este contexto en el que encontramos el llamamiento y ministerio de Jefté. ${ }^{35}$ La crónica sobre Jefté está registrada en los capítulos 11 y $12 .{ }^{36}$

Texto y contextos: Jueces 11:34

La perícopa engloba los capítulos 10 al 12. En 11:30 y 31, se dice: "y Jefté hizo voto a Jehová, diciendo: Si entregares a los amonitas en mis manos, cualquiera que saliere de las puertas de mi casa a recibirme, cuando regrese victorioso de los amonitas, será de Jehová, y lo ofreceré en holocausto". ${ }^{37}$ En Jue 11:39 se afirma que el padre "hizo de ella conforme al voto que había hecho”. La BH prohíbe los sacrificios humanos ( $\operatorname{lv}$ 18:21 y 20:1-5), aunque parece que esta práctica no siempre fue observada. Saúl casi sacrifica a

\footnotetext{
35Para más información, véase Daniel I. Block, Judges-Ruth, The New American Commentary 6 (Nashville, TN: Broadman \& Holman, 1999).

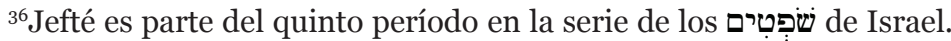
Primer período: Otoniel. Segundo: Aod y Samgar. Tercero: Débora y Barac. Cuarto: Gedeón, Tola y Jair. Quinto: Jefté, Ibzán, Elón y Abdón. Sexto: Sansón. Véase Jue 3:7 a 16:31.

${ }^{37}$ Cursiva añadida.
} 
su hijo Jonatán después de hacer un voto (1 S 14:24-25). En 2 S 21:1-14 encontramos un incidente que da margen para, por lo menos, dos interpretaciones que implican el sacrificio o la ejecución de humanos..$^{38}$ En Jer 7:31 se habla de sacrificios de niños hechos durante el período de la decadencia espiritual de Jerusalén antes del exilio a Babilonia (cf. Lm 4:10).

Lo que importa para nuestra investigación aquí no son las cuestiones ético-religiosas, sino la semántica de ירָיחיד en este contexto.

Jueces 11:34: Entonces volvió Jefté a Mizpa, a su casa; y he aquí su hija que salía a recibirle con panderos y danzas, y ella era sola, su hija única; no tenía fuera de ella hijo ni hija.

Estructura del texto:

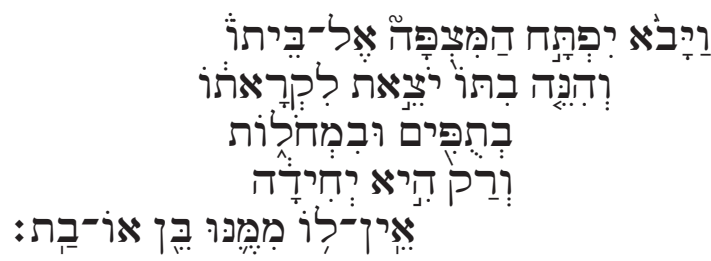

ריחיד es usado en este verso como adjetivo femenino

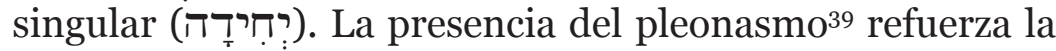
idea central de רְיחיד: unicidad y singularidad. Un dato intri-

${ }^{38}$ Este incidente puede ser entendido como un acto judicial-político o como judicial-religioso (sacrificios humanos en montes eran comunes en el mundo antiguo). Las dos cláusulas, (1) "delante de Jehová” (v. 9) y (2) “y Dios fue propicio a la tierra después de esto" (v. 14), parecen evocar un gran valor sustitutivo y expiatorio.

${ }^{39}$ Este fenómeno lingüístico es también conocido como acusativo cognato semítico. Lambdin, Gramática do Hebraico Búblico, 148. "Y había un hombre de Zora, de la tribu de Dan, el cual se llamaba Manoa; y su mujer era estéril, y nunca había tenido hïos" (Jue 13:2). Cursiva añadida. 


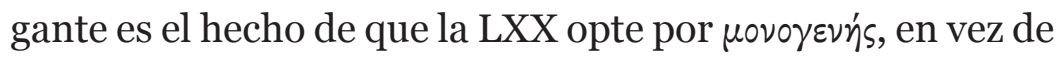

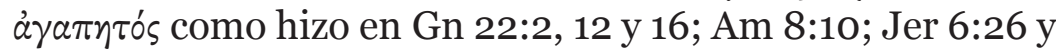
Zac 12:10.40 El significado de hija única, unigénita.

Síntesis de ריחיד en Jueces

Existe una relación muy próxima entre Jueces y Génesis en lo que dicen respecto al concepto de ירדידיד. Los personajes en estos dos libros tienen un papel actancial muy semejante.

\begin{tabular}{|c|c|}
\hline Isaac - Gn 22 & Hija de Jefté - Jue 11 \\
\hline $\begin{array}{c}\text { Sometido al "voto" que su } \\
\text { padre ha hecho }\end{array}$ & $\begin{array}{c}\text { Sometido al voto que su } \\
\text { padre ha hecho }\end{array}$ \\
\hline Es virgen & Es virgen \\
\hline $\begin{array}{c}\text { Fue sumiso a la voluntad } \\
\text { del padre }\end{array}$ & $\begin{array}{c}\text { Fue sumisa a la voluntad } \\
\text { del padre }\end{array}$ \\
\hline $\begin{array}{c}\text { "unigénito" - } \\
\text { "primogénita" - } \\
\text { "primogénito" }\end{array}$ \\
\hline Se menciona el nombre & No se menciona el nombre \\
\hline Es hombre & Es mujer \\
\hline Es salvado & "sacrificada" \\
\hline $\begin{array}{c}\text { Espacialización: Monte } \\
\text { Moriah }\end{array}$ & Espacialización: Montes \\
\hline
\end{tabular}

Tabla: Isaac y la hija de Jefté

Los opuestos binarios que estructuran estas dos narrativas posibilitan contaminaciones semánticas que de alguna forma habrían influido en la interpretación de en

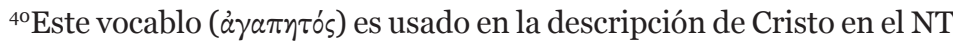
como se evidencia en Mt 3:17; 17:5; Mc 1:11; 12:6; Lc 3:22; 20:13; 2 P 1:17. 
Génesis pues la LXX no "traduce" יִחידיד sino que hace una interpretación contextual. La estructura narrativa sugiere que la audiencia conocía bien el término y su uso en aquel contexto. Sin embargo, cuando se usó יִָָיד en Jueces se necesitó utilizar de un pleonasmo para no dejar margen de duda en cuanto al significado intencionado (Jue 11:34). Es posible que para entonces el vocablo ya hubiera sufrido los efectos de una evolución semántica y se deseara delimitar con rigor su intención conceptual. Es posible también que este suceso haya servido de inspiración semántica para interpretar en en Génesis.

El sentido de יִחידיד en Jueces es el más evidente entre todos los textos del Tanaj en los que aparece este término. Aquí יחָידיד significa tanto unigénita como primogénita o úni-

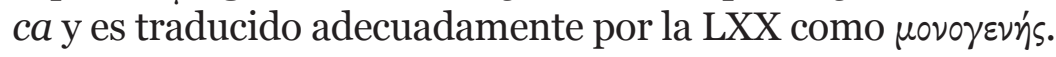

\section{eר en Jeremías}

\section{Propedéutica}

La espacialización de los eventos del libro de Jeremías sucede en la tierra de Israel y Judá. La temporalización abarca el período previo al exilio babilónico. La trama narrativa describe el declive de las instituciones, la apostasía individual y colectiva, la injusticia social, la relativización de los patrones morales y las amenazas de invasión extranjera. La producción oral y escrita de los oráculos de Jeremías provocó una tensión interna en el escenario político y religioso de Jerusalén. La actorialización involucra a Jehová, Jeremías, Baruc, al liderazgo judío y a los jefes de las potencias bélicas invasoras. ${ }^{41}$

${ }^{41}$ Para información adicional, véase Robert B. Chisholm Jr., "A Theology of Jeremiah and Lamentation", en A Biblical Theology of the Old Testament, ed. Roy B. Zuck (Chicago: Moody Press, 1991), 341-65. 
Texto y contextos: Jeremías 6:26

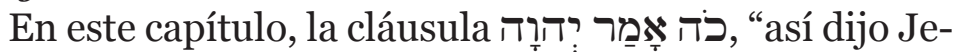
hová”, que aparece en los vv. 6, 16, 21 y 22, estructura prácticamente todos los discursos del libro reivindicando la autoridad divina de los oráculos proféticos. ${ }^{42}$ El contexto inmediato abarca los capítulos 4 al $6 .{ }^{43}$ El género es una mezcla de prosa y poesía y un estilo literario de un inquiridor oculto que hace indagaciones retóricas donde Jehová cuestiona el comportamiento indiferente del pueblo elegido. El tema del juicio inminente y la invitación al arrepentimiento están contenidos en este pasaje. El núcleo de la narrativa, un tanto sombría, evoca un ambiente fúnebre de un ente querido definido como יחדידיד. El texto de Jer 6:26 cierra la última parte del oráculo en forma de diálogo (vv. 23-30).44 En un sentido general, el capítulo habla del conflicto entre dos mundos etno-espirituales.

No nos vamos a centrar en el análisis de todos los detalles asociados al texto, sino solamente en los aspectos que nos proporcionen elementos de interés para la reconstrucción semántica de

Jeremías 6:26: Hija de mi pueblo, cíñete de cilicio, y revuélcate en ceniza; ponte luto como por hijo único, llanto de amarguras; porque pronto vendrá sobre nosotros el destruidor.

Estructura del texto:

${ }^{42} J e r$ 2:2, 4:27; 6:16, 22; 10:2; 12:14; 19:15; 23:2; 38:2; 50:18, 51:58, etc.

${ }_{43}$ Para un estudio más detallado sobre esta perícopa, véase Robert Althann, A Philological Analysis of Jeremiah 4-6 in the Light of Northwest Semitic, 1983, citado en Peter C. Craigie, Jeremiah 1-25, WBC 26 (Dallas, TX: Word, 2002), 44.

44 Ibíd., 108. 


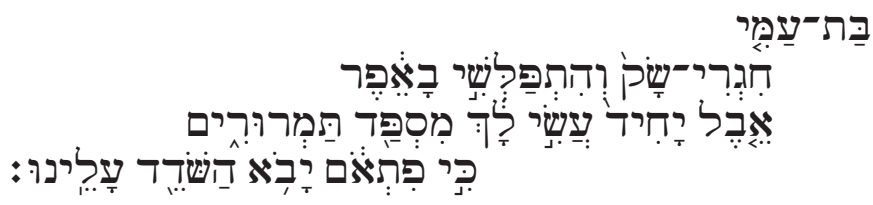

El sintagma empieza con un estado constructo en tono vocativo. La expresión "hija de mi pueblo", כבּת (v. 26),

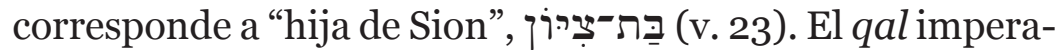
tivo femenino singular (חִגְרי, "cíñete") es usado para encabezar una lista de procedimientos relacionados con un escenario de luto y juicio. ידָידיד tiene aquí la función de un sus-

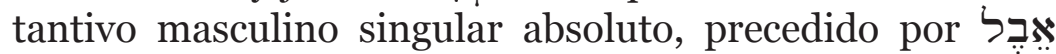
("llanto, luto") como cabeza del estado constructo. El sentido, según el contexto, tanto podría ser de un "hijo único", "unigénito" (unigeniti, Vulgata) o "primogénito" (NVI), aunque las dos primeras opciones se ajustan más al cuadro general. La LXX transporta la semántica de יחדיד de Génesis

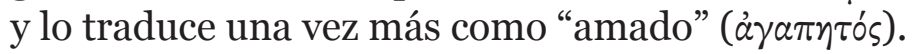

Síntesis de רִָ en Jeremías

Siguiendo la pragmática general de יִחידיד en el Tanaj, aquí conserva su función fundamental que es definir a alguien como "único" o "muy especial”.

\section{en Amós}

Propedéutica

Como unidad literaria, este corpus está compuesto prácticamente por un género poético casi en su totalidad con un estilo retórico muy peculiar. ${ }^{45}$ Amós era un agricultor-poeta que vivió en el reino del sur (Judá-Jerusalén), pero su mi-

${ }^{45}$ Charles Dyer, et al., Nelson's Old Testament Survey: Discover the Background, Theology and Meaning of Every Book in the Old Testament (Nashville, TN: Word, 2001), 745-62. 
nisterio profético fue desarrollado en el reino del norte (Israel-Samaria). Su libro contiene un grupo de declaraciones de juicio -como el "día amargo" (8:10) - que es el día del ajuste

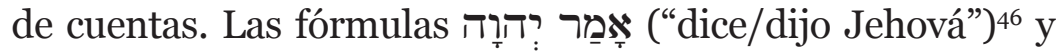

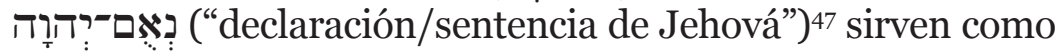
hilo conductor de los discursos a lo largo del libro. ${ }^{48}$

Texto y contextos Amós 8:10

El texto es una poesía profética y forma parte del bloque temático de oráculos dirigidos al reino del norte. El contenido es una amenaza de cambiar el ambiente festivo por un escenario fúnebre: el fin inminente de Israel está asegurado. El juego de palabras en el inicio del capítulo 8 es significativo: קָקי, "fruta de verano", y pro, "fin" (v. 2).49 Las figuras de llanto y luto ilustran el nivel del declive moral y espiritual..$^{5} \mathrm{El}$ texto está compuesto en pares de sentencias sinónimas. La perícopa abarca todo el capítulo 8.

Amós 8:10: Y cambiaré vuestras fiestas en lloro, y todos vuestros cantares en lamentaciones; y haré poner cilicio sobre todo lomo, y que se rape toda cabeza; y la volveré como en llanto de unigénito, y su postrimería como día amargo.

${ }^{46} \mathrm{Am} \mathrm{1}: 3,5-6,9,11,13,15 ; 2: 1,3-4,6 ; 3: 12 ; 5: 4,16-17,27 ; 7 .: 3,17 ; 9: 15$.

${ }^{47}$ Am 2:11, 16; 3:10, 13, 15; 4:3, 5-6, 8-11; 6:8, 14; 8:3, 9, 11; 9:7-8, 12-13.

${ }^{48}$ Para más información sobre el estilo literario de Amós, véase Hans Walter Wolff y S. Dean McBride, Joel and Amos: A Commentary on the Books of the Prophets Joel and Amos, Hermeneia: A Critical and Historical Commentary on the Bible (Philadelphia: Fortress Press, 1977), 91-4.

${ }^{49}$ Para información adicional, véase William Rainey Harper, A Critical and Exegetical Commentary on Amos and Hosea (New York: C. Scribner's Sons, 1905), 174-85.

50Ibíd., 329. 
Estructura del texto:

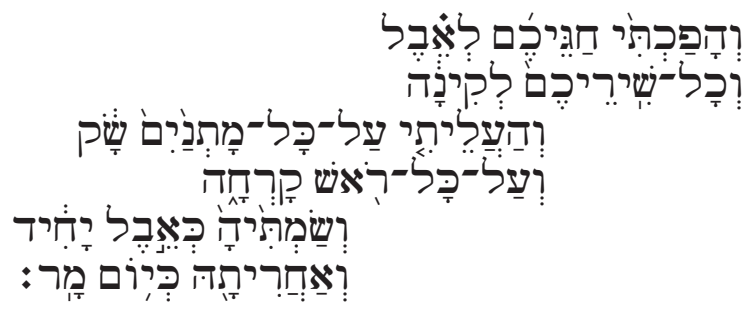

Jeremías y Amós, profetas del pre exilio babilónico,

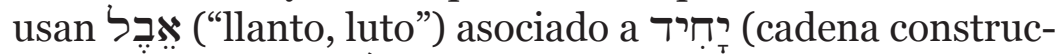
ta). Amós recurre a אִ יָבל dos veces en este verso, formando

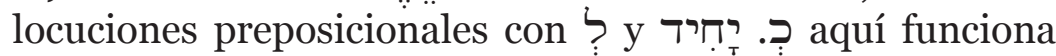
con un sustantivo masculino singular absoluto. Las senten-

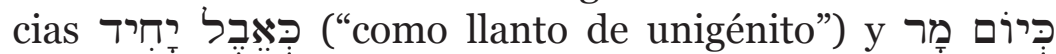
("como día amargo") pueden ser consideradas como un paralelismo sinónimo.

Síntesis de יחידיד en Amós

La pragmática y la semántica de ריד en en Amós no difiere del libro de Jeremías. Su significado de "unigénito" o "hijo único" se ajusta correctamente a todos los contextos. A pesar de ello la LXX mantiene la misma línea que en Génesis-Jere-

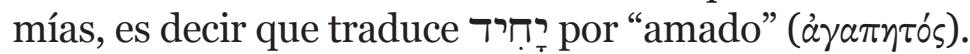

\section{en Zacarías}

Propedéutica

El contexto literario en el que se encuentra nuestro pasaje es la segunda parte del libro de Zacarías (capítulos 9 al 14). ${ }^{51}$ Lo mismo que con los otros corpus, consideramos esta

${ }^{51}$ Sobre la estructura general del texto, véase David J. Clark y Howard Hatton, A Handbook on Zechariah (New York: United Bible Societies, 2002), 308-26. 
obra como una unidad literaria. En Zacarías prevalece la poesía, aunque la prosa organiza el desarrollo argumentativo. La espacialización es Jerusalén, entendida aquí como una sinécdoque representando el reino unificado. La temporalización es la era escatológica del juicio futuro. La actorialización en el plan narrativo está constituida por binomios:

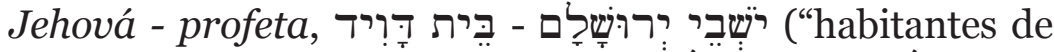

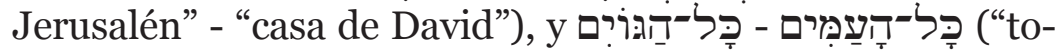
dos los pueblos" - "todas las naciones"). La temática central es el triunfo futuro de Jerusalén.

Texto y contextos: Zacarías 12:10

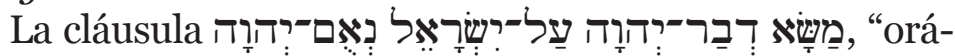
culo de la palabra de YHWH sobre Israel, declara YHWH" (Zac 12:1), ${ }^{52}$ inicia el capítulo y da el tono del discurso. La voz מַשָָָׁ ("oráculo, sentencia, declaración”), en general, evoca una audiencia judicial..$^{53}$ En Jeremías y Amós, el luto, llanto, lloro o lamentación (אבֶב (אבל) es usado para definir el tipo de castigo que sobrevendría sobre los reinos del norte y del sur. En Zacarías, en cambio, en la lamentación hay un elemento positivo. Jerusalén será vindicada por el "espíritu de gracia y de ora-

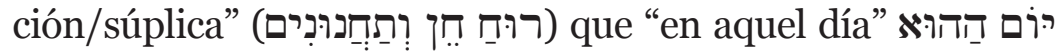
(Zac 12:11) producirá el sentimiento de מִọֵ (llanto, lloro, luto, lamentación) ${ }^{54}$ sobre la "casa de David", es decir, la dinastía de David y los demás "moradores de Jerusalén" (por extensión, todo el reino unificado). La ideología mesiánica se

${ }^{52}$ Traducción propia.

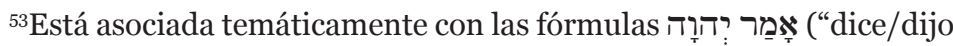

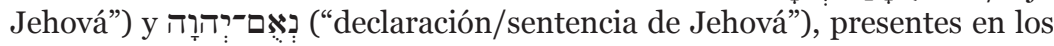
escritos proféticos.

${ }^{54} \mathrm{Gn}$ 50:10; Est 4:3; Sal 30:12; Is 22:12; Jer 6:26; 48:38; Ez 27:31; Jl 2:12; Am 5:16-17; Mi 1:8, 11; Zac 12:10-11. 
encuentra fuertemente presente en el libro de Zacarías. ${ }^{55}$

El contexto inmediato es todo el capítulo 12, y se amplía hasta el 13 y 14, temáticamente conectados.

Zacarías 12:10: Y derramaré sobre la casa de David, y sobre los moradores de Jerusalén, espíritu de gracia y de oración; y mirarán a mí, a quien traspasaron, y llorarán como se llora por hijo unigénito, afligiéndose por él como quien se aflige por el primogénito.

Estructura del texto:

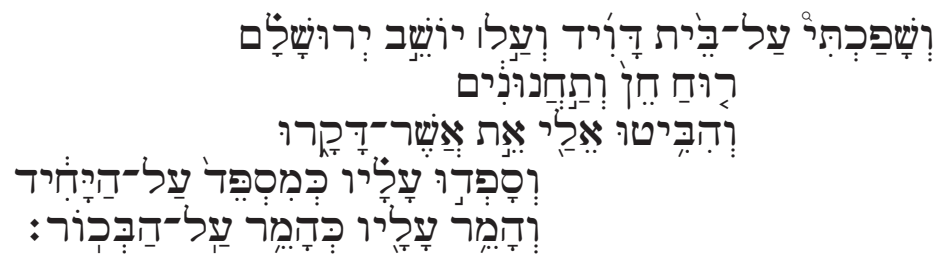

Las últimas dos cláusulas que empiezan con la conjunción ר, aquí con función copulativa, están estructuradas se-

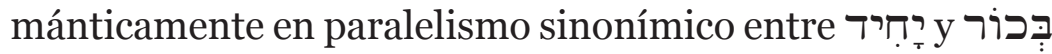

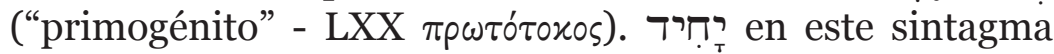
tiene función de adjetivo.

Síntesis de רִיָּריד en Zacarías

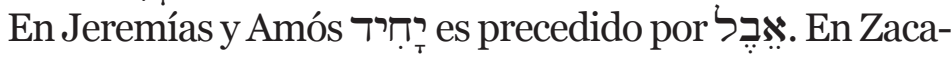

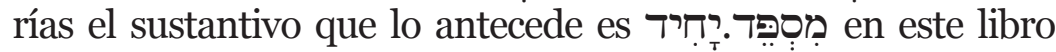
puede ser traducido por "unigénito" (unigeniti, Vulgata), "hijo predilecto” (NJPS), "único hijo” (Complete Jewish Bible), “ama-

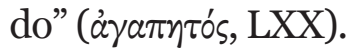

${ }^{55}$ Para un estudio sobre los aspectos literarios de Zacarías, véase Ralph L. Smith, Micah-Malachi, WBC 32 (Dallas, TX: Word, 2002), 165-81. 


\section{en los Ketuvim (Escritos)}

La labor de la traducción es per se una tarea muy compleja ${ }^{56}$ y la semántica de un texto se encuentra siempre íntimamente asociada al mismo acto de la traducción. Esta, a su vez, depende no solo del contexto puntual, sino también de la pragmática del término en consideración a otras situaciones. ירָיד en los Ketuvim poéticos marca una línea semántica distinta de su pragmática en otros libros del canon hebreo.

\section{en los Salmos}

\section{Propedéutica}

Vamos a reflexionar sobre los textos en cuestión, pero teniendo siempre presente la naturaleza del género literario de los Salmos. La poesía hebrea antigua, como las demás de las lenguas semíticas, ${ }^{57}$ tiene especificidades que difieren significativamente de la escrita en idiomas modernos..$^{8}$ Este género literario se encontraba involucrado en la liturgia, los conflictos bélicos, los oráculos proféticos y en la vida cotidiana con todo su abanico emocional (venganza, llanto, lamento, júbilo, alegría, muerte, vida, alabanzas, etc.).

${ }^{56}$ Geir Campos, O que é Tradução (São Paulo: Brasiliense, 1986); Robert G. Bratcher y William David Reyburn, A Translator's Handbook on the Book of Psalms: Helps for Translators (New York: United Bible Societies, 1991), 1-13; Lynell Zogbo y Ernst Wendland, La poesía del Antiguo Testamento: Pautas para su traducción, trad. Alfredo Tepox Varela (Miami: Sociedades Bíblicas Unidas, 2000), 1-20.

${ }^{57}$ C. Hassell Bullock, An Introduction to the Old Testament Poetic Books (Chicago: Moody, 1988), 19-67.

${ }^{5}$ James E. Smith, The Wisdom Literature and Psalms (Joplin, MO: College Press, 1996). 
Textos y contextos

Los salmos aquí estudiados están ubicados en la BH en el Libro I (22, 25 y 35) y en el Libro II (68). Nuestro enfoque estará exclusivamente centrado en la semántica de רִחיד

Salmo 22:2o (TM v. 21). Este salmo empieza con un tono melancólico. Está compuesto alrededor de una alternancia de sentimientos que marca una musicalidad y un ritmo poéticos. Este verso es muy similar en estilo a Sal 35:17. La temática incluye elementos como: sufrimiento, abandono, injusticia, violencia, etc.

Salmos 22:20 (TM v. 21): Libra de la espada mi alma, del poder del perro mi vida.

Estructura del texto:

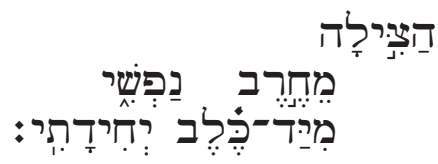

El verbo que abre el verso está seguido de un i paragógico, cuyo propósito es el de enfatizar el sentido. ${ }^{59}$ La locución

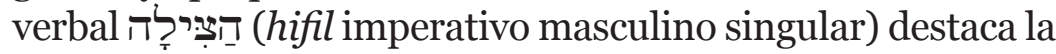
acción causativa ejecutada por el sujeto. Las dos cláusulas yuxtapuestas tienen como antecedentes la preposición מ̣̂. Se trata de una disposición asindética. Las dos oraciones componen un paralelismo sinonímico. ${ }^{60}$ En ambas expresiones (“de la espada” y "del poder del perro") implica muerte vio-

${ }^{59}$ Paul Joüon y Takamitsu Muraoka, A Grammar of Biblical Hebrew (Roma: Editrice Pontificio Istituto Biblico, 2003-2005), 1:138.

${ }^{60}$ Véase Peter C Craigie, Psalms 1-50, WBC 19 (Dallas, TX: Word, 2002), 197. 


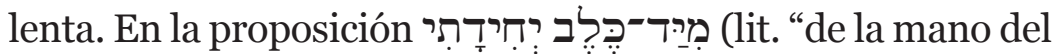

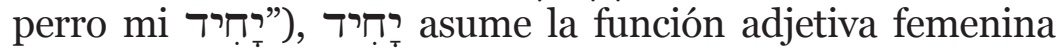
singular constructa, sufijo de primera persona singular.

Sobre el significado de יִָָ en este versículo no existe consenso entre los estudiosos y exégetas. Las versiones con propuestas diferentes acerca del sentido de רָדיד en este texto son múltiples. ${ }^{61}$ El Tárgum de los Salmos tradujo רָידיד por "espíritu de mi cuerpo" (רוחא דגושמי). de ירדיד por "vida" es deducida del paralelismo poético del

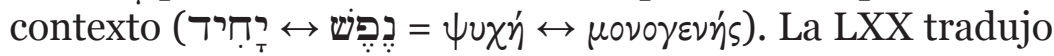

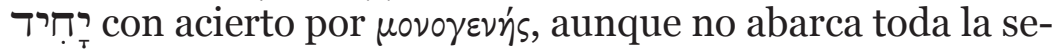
mántica de יָחידיד en este contexto. La Vulgata propuso unicam meam. Así, según este contexto, ירדיד sugiere ideas tales como: "mi única", "mi única vida", "mi alma", "mi vida", "mi ser" y "mi existencia".

Salmo 25:16. La perícopa abre con un vocativo y cierra con un imperativo. Su temática es la petición de auxilio, confianza en la providencia, la angustia, la soledad, el abandono y la reivindicación de la justicia.

Salmos 25:16: Mírame, y ten misericordia de mí, porque estoy solo y afligido.

Estructura del texto:

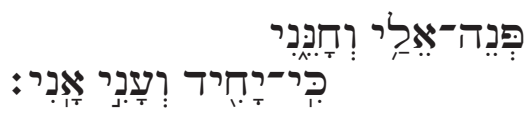

${ }^{61}$ E.W. Hengstenberg, Commentary on the Psalm (Edinburgh: T \& T Clark, 2007), 1:389.

${ }^{62}$ Stephen A. Kaufman, ed., Targum Psalms (Cincinnati: Hebrew Union College, 2005). 
En el preludio del verso, la cláusula verbal traducida

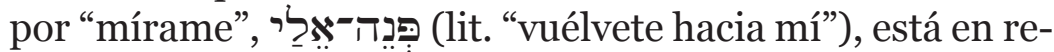
lación con "mis ojos están siempre [dirigidos] hacia Jehová" (v. 15). En la segunda parte del versículo, יָדידיד constituye un elemento de una oración subordinada en la que ejerce la función de sustantivo y se encuentra en paralelismo con רִִָני ("pobre, afligido, humilde"). La semántica de יִִָיד aquí es la antítesis a la presentada en Gn 22. Mientras que en Génesis ירָידיד está vinculado al concepto de proximidad, cercanía, estar junto, en este salmo רְידיד pinta un cuadro de abandono, soledad, pobreza. El ירידיד es uno que clama a YHWH para que vuelva (v. 16), lo que implica la noción de lejanía. Mientras en Gn 22 el רִִָיד es el heredero de la parte más grande de la herencia, en el versículo en consideración aquí, el ירָיד es un ser desprovisto, desvalido, afligido, solitario.

La Vulgata vertió ירָיד como unicus. La LXX (24:16), a

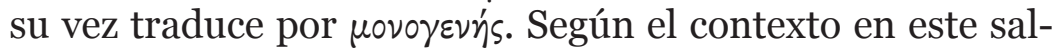
mo רִידִיד puede ser entendido como "solo", "solitario", "separado" y "aislado".

Salmo 35:17. La formulación del texto es un clamor por la justicia y una declaración de confianza en la intervención divina. El versículo aquí analizado tiene una equivalencia temática y estructural muy próxima a Sal 22:20. Lo que dijimos allí puede ser, en cierto modo, aplicado aquí.

Salmo 35:17: Señor, ¿̇hasta cuándo verás esto? Rescata mi alma de sus destrucciones, mi vida de los leones.

Estructura del texto:

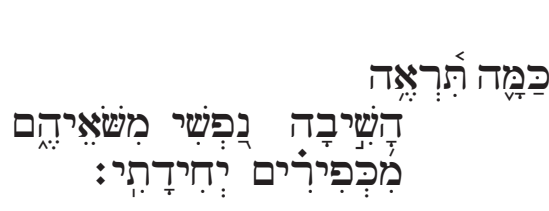

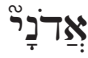


El i paragógico, que es un elemento de énfasis capaz de modificar el término al que se acopla y que en el Sal 22 encontramos en el inicio del v. 20 (הָצבירָדיה, "libra"), aquí ha sido colocado en la segunda mitad del versículo, דָשִׁיבָה ("rescata", lit. "trae de vuelta", hifil imperativo). Las dos frases, "mi alma de sus destrucciones" y "mi vida de los leones" se encuentran en disposición de paralelismo sinonímico. La

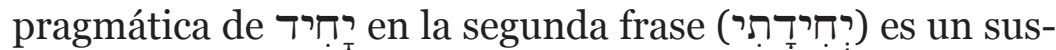
tantivo femenino sufijado (primera persona singular). La inferencia de רָיחיד por "vida" es deducida del paralelismo

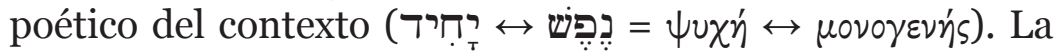

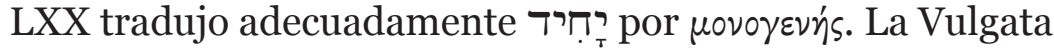
optó por unicam meam. El Tárgum de los Salmos lo traduce por "mi cuerpo". Así, según los contextos, רדיחיד alude a ideas tales como "mi única", "mi única vida", "mi alma”, "mi vida", "mi ser" y "mi existencia".

Salmo 68:5-6 (TM vv. 6-7). La argumentación gira en torno al clamor por la justicia, la teofanía en el Sinaí y en el santuario, la exaltación de la bondad de YHWH.

Salmo 68:5-6 (TM vv. 6-7): Padre de huérfanos y defensor de viudas, es Dios en su santa morada. Dios hace habitar en familia a los desamparados; saca a los cautivos a prosperidad; mas los rebeldes habitan en tierra seca.

Estructura del texto:

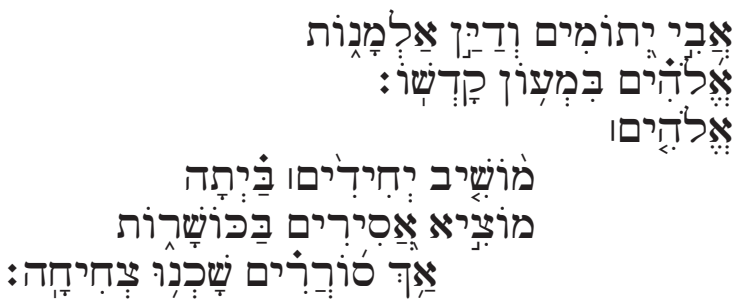


El orden de las palabras en el inicio de los versos denota el énfasis planteado. En ambos casos el sujeto es el mismo -YHWH-. En este texto יָדיד tiene el papel de sustantivo común masculino plural. Su aspecto semántico puede estar relacionado con Gn 22. Por otra parte, en Génesis, יִִָ es aquel que posee una casa, padres, está protegido, es el único heredero prometido. En cambio, en el texto que estamos considerando aquí יָ דִיד adquiere una connotación muy distinta y semejante a Sal 25:16 - uno que está desprovisto de prácticamente todo-. La LXX lo

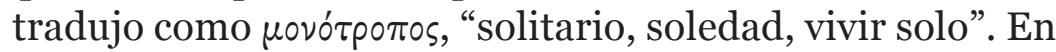
Génesis, Isaac, el dָדִידיד de Abraham, vive en familia. Ismael el anti יָדִיד, grosso modo, vive en el desierto. De ahí que רָדִיד en este salmo y en el Sal 25 tenga una semántica radicalmente contrapuesta.

ריִָידיד, como ya hemos visto, es un término polisémico. ${ }^{63}$ En este salmo ירזיד define a alguien en estado de profunda necesidad y sin alternativa aparente.

Síntesis de en Salmos

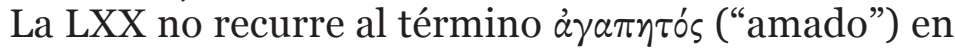
ningún lugar de los Salmos. La pragmática de יָדיד en Sal 22, 25, 35 y 68 estableció una plataforma semántica distinta a la de los otros pasajes de la $\mathrm{BH}$. Creemos que estos salmos, atribuidos por la tradición hebrea a David, evidencian en cierto modo una evolución semántica del término דיָחיד Teniendo en cuenta que la experiencia existencial de David fue muy semejante a los aspectos semánticos aquí agregados a יָּחיד, podemos deducir que tal vez sí exista un hilo conductor.

${ }^{63}$ Véase Marvin E. Tate, Psalms 51-10o, WBC 20 (Dallas, TX: Word, 2002), 163 . 


\section{en Proverbios}

Propedéutica $^{64}$

Algunos proverbios son atribuidos a "Salomón, hijo de David, rey de Israel” (Pr 1:1). ${ }^{65}$ La perícopa abarca del capítulo 1 al 9. La temática es la de las exhortaciones para alcanzar la sabiduría y la práctica de la obediencia.

\section{Texto y contextos: Proverbios 4:3}

El texto presenta algunas variantes textuales, pero nada que altere significativamente la semántica del versículo. ${ }^{66}$ El contenido son los consejos de un padre-maestro a sus hïos-discípulos.

Proverbios 4:3: Porque yo también fui hijo de mi padre, delicado y único delante de mi madre.

Estructura del texto:

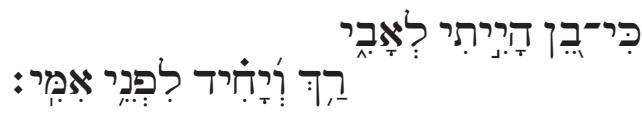

En la división de este verso seguimos la puntuación (cantilación, atnah) de la BHS. ריחידיד aquí es un adjetivo masculino singular absoluto. El contexto no ofrece informaciones suficientes como para establecer un aspecto semántico seguro.

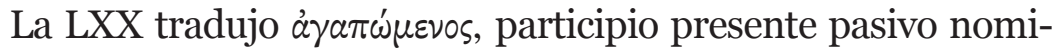

${ }^{64}$ Para una introducción al libro de Proverbios, véase Rowland E. Murphy, Proverbs, WBC 22 (Dallas, TX: Word, 2002), xviii-xxix.

${ }^{65}$ Los textos de 1 R 3:11; 4:29-34 sugieren que aunque es posible que una parte fuera escrita por él, es evidente que no toda la colección lo fue.

${ }^{66}$ Véase Crawford Howell Toy, A Critical and Exegetical Commentary on the Book of Proverbs (New York: C. Scribner's Sons, 1899), 89. 


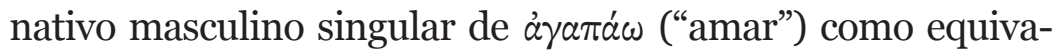
lencia de יִחיד. La Vulgata lo vertió como unigenitus, "unigénito" (Pr 4:3). El Tárgum de Proverbios mantuvo la acepción tradicional de "único" (יחידא).67

Síntesis de ריחיד en Proverbios

En Pr 4:3, ירחיד incorpora rasgos semánticos similares a los de Gn 22. De acuerdo con el contexto general, "elegido" puede ser una adecuada traducción ya que Salomón no era el único hijo de David, sino el único heredero al trono (véase $1 \mathrm{Cr}$ 29:1).

\section{Diacronía de רָיחיד}

ירחיד inicia su trayecto semántico de forma ambigua. Su uso en Gn 22:2 engloba un tipo de unicidad parcial (ya que Isaac no era el único hijo de Abraham) y al mismo tiempo añade la dimensión de afecto expresado en la idea de proximidad. ידָידיד aparece registrado en 7 libros de la BH. Como "único o unigénito" (Jue 11:34; Jer 6:26; Am 8:10 y Zac 25:16); como "amado, elegido, el único heredero elegido" (Gn 22:2, 12, 16 y Pr 4:3); como "vida/alma" (Sal 22:21 y 35:17); como "solo, solitario, abandonado" (Sal 25:16 y 68:7). La voz ירָידיד es usada 12 veces en la BH en 12 versículos con 5 formas distintas. ${ }^{68} \mathrm{El}$ desarrollo del concepto de רִ יָחיד en el Tanaj resulta complejo debido al reducido número de versículos en los que aparece, limitando la compresión de dicho desarrollo a los pasajes aquí analizados.

En el recorrido semántico que hemos hecho por el Ta-

${ }^{67}$ Stephen A. Kaufman, ed., Targum Proverbs (Cincinnati: Hebrew Union College, 2005).

68 ריחִיד aparece en Gn 22:2, 12, 16; Jue 11:34; Sal 22:21; 25:16; 35:17; 68:7; Pr 4:3; Jer 6:26; Am 8:10; Zac 12:10. 
naj, podemos verificar contextualmente la pragmática que generan las connotaciones semánticas originales de la voz יִָידיד. Es curioso que en Gn 22:2, 12, 16; Jue 11:34, Jer 6:26, Am 8:10 y Zac 12:10; יחיד está asociado directamente a la muerte. ${ }^{69}$ Esto resulta significativo considerando lo que representaba para las sociedades antiguas el fallecimiento del hijo único. El concepto de יִִָיד, sin embargo, se fue desarrollando a lo largo de la historia de la lengua hebrea, y fue agregando aspectos semánticos que, en algunos casos, eran totalmente distintos de su base semántica original.

\section{Implicancias cristológicas}

Según los autores del NT, Jesús es el ירָיד de Dios.7º́l Él es el "amado", "unigénito", "primogénito", "abandonado", "solitario", "elegido", y "único heredero". Se puede añadir a estos conceptos la idea de ידָידיד asociada con la muerte y amenazas de muerte - todas estas ideas son oriundas de en el TM y en la LXX-. Por ende, el NT se apodera de estas elaboraciones y las aplica al Mesías. Jesús es interpretado como "el amado de Dios" (véase Mt 3:17, 12:18, 17:5) y "uno" (عiّ) con el Padre (Jn 10:30).71

La iglesia en cierto sentido también vivencia esta se-

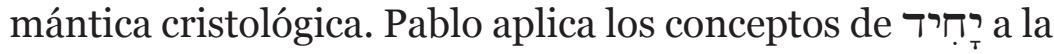
comunidad cristiana. La teología del יִָָ prefigura tanto los conceptos-eventos cristológicos como los eclesiológicos. Tipológicamente hablando, es como si los hechos históricos y existenciales del pueblo de Israel prefigurasen al Mesías, y

\footnotetext{
${ }^{69} \mathrm{En}$ Sal 22; 25:16; 35:17 y 68:7 subyace la amenaza de muerte.

${ }^{70}$ Mt 3:17; 12:18; 17:5; Mc 1:11; 9:7; 12:6; Lc 3:22; $20: 13$.

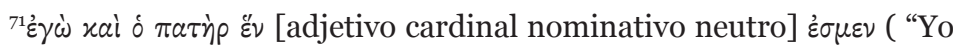
y el Padre uno somos").
} 
los de Jesucristo anticipasen los de la iglesia en el desierto de este mundo antes de la parusía...

Evandro Luiz da Cunha pastorevandro7@yahoo.com.br

Universidad de Barcelona

Barcelona, España

Recibido: 10/02/2016

Aceptado: 20/01/2017 